\title{
PRÉSTAMOS, INTERCAMBIOS Y ROBOS COMPOSITIVOS EN EL CUBISMO SINTÉTICO PARISINO DE FINALES DE LOS AÑOS DIEZ
}

Belén Atencia Conde-Pumpido

Universidad de Málaga

Data de recepción: 2019-07-04

Data de aceptación: 2020-07-03

Contacto autora: batencia@uma.es

ORCID: https://orcid.org/0000-0001-7926-9536

\section{RESUMEN}

Al inicio de la Primera Guerra Mundial el grupo cubista se reorganiza. Los límites antes establecidos entre aquellos que exponían en los salones y los cubistas contratados por Kahnweiler desaparecen y todos ellos pasarán a integrar un único grupo. Aparecen nuevas técnicas y temáticas que hacen dudar a algunos sobre la legitimidad de ciertos integrantes del nuevo grupo cubista. Algunas de estas dudas son plasmadas en artículos firmados por aquellos que en un principio, parecen defender el movimiento ante la imperante demanda del retorno al orden. Este artículo pretende sondear las similitudes presentes en algunas de las obras realizadas por algunos de estos artistas con el fin de establecer posibles préstamos e influencias que pudieran justificar sus interrelaciones.

Palabras clave: vanguardias artísticas, cubismo, guerra, galería L'Effort Moderne, Léonce Rosenberg

\section{ABSTRACT}

The Cubists reorganised at the beginning of the First World War. The boundaries that had hitherto existed between the artists who exhibited in the salons and the Cubists commissioned by Kahnweiler disappeared as they merged to form a single group. The emergence of new techniques and themes caused some to doubt the legitimacy of certain members of this new formation. Some of these doubts are expressed in articles written by those who, at first, seemed to defend the movement against the prevailing demand for a return to order. This paper aims to explore the similarities in some of these artists' works with a view to identifying possible loans and influences that could explain the interrelationships between them.

Keywords: artistic avant-gardes, Cubism, war, L’Effort Moderne Gallery, Léonce Rosenberg

\section{Críticas y susceptibilidades}

Cuando Pierre Reverdy inauguró la revista Nord-Sud aseverando su disgusto frente a esos pseudo-cubistas, quienes pretendiendo hacer retratos a la manera cubista, olvidan que el objetivo último es el de crear un cuadro y no una cabeza construida según las nuevas leyes del arte (Reverdy 1917), seguramente nunca imaginó el rompecabezas que para los historiadores del arte constituiría esta afirmación. No fue el único en encontrar "poco cubista" la temática retratística, todo hay que decirlo. Amédée Ozenfant arrojaba similares acusaciones en su neonata L'Élan contra los cubistas primarios, cuya última voluptuosidad era la de sacar a golpe de escuadra la cara de sus mujeres (Ozenfant, 1916). La crítica resulta 


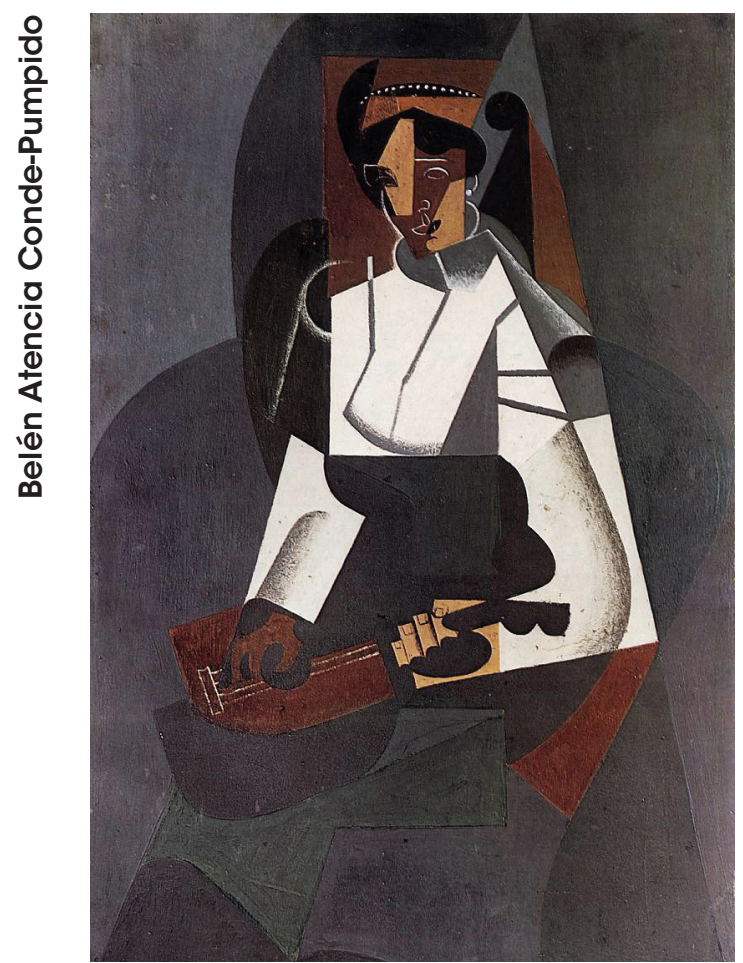

Fig. 1. Juan Gris, Muchacha con mandolina, 1916, óleo sobre lienzo, $92 \times 60 \mathrm{~cm}$, Kunstmuseum de Basel

cuanto menos curiosa, considerando que ambos se habían posicionado desde el inicio de la contienda del lado del cubismo y que, en estos años en los que se demanda taxativamente le rappel à l'ordre, tanto uno como otro muestran una clara voluntad de mantener viva la vanguardia.

Pero, ¿de qué o de quiénes necesitaba ser defendido el cubismo? Lo cierto es que un poco de todo y de todos. El desmembramiento de la vida artística parisina entre 1914 y los primeros años de la década de los veinte, no le pusieron las cosas fáciles. Al forzoso exilio de Kahnweiler y el reclutamiento de no pocos de sus miembros, se une la diáspora artística de aquellos que tuvieron la suerte de no ser llamados a filas'. Las galerías cerraron, los coleccionistas y compradores se marcharon y a París no le fue sencillo revivir culturalmente de los horrores de la guerra. Sabemos que se mantuvieron, aún con muy escasa actividad, la Galerie Weill, la Boutet de Monvel, la Paul Guillaume y la Bernheim Jeune. Además de ello,

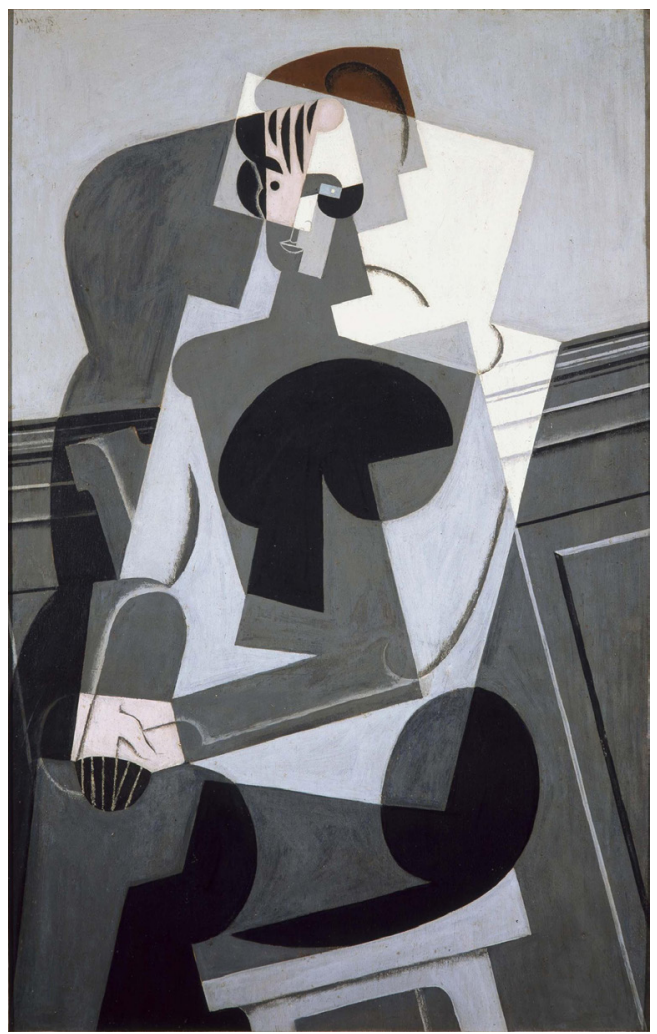

Fig. 2. Juan Gris, Retrato de Josette, 1917, óleo sobre tabla, $116 \times 73 \mathrm{~cm}$, Museo Nacional Centro de Arte Reina Sofía, Madrid

no podemos olvidar las exposiciones celebradas ente 1915 y 1916 en el seno del taller de costura de Mme. Germaine Bongard, hermana de Paul Poiret, en las que el propio Ozenfant elegía las obras a exponer, o las asociaciones Art et Liberté y Lyre et Palette, en las cuales se organizaban con cierta frecuencia exposiciones y encuentros artísticos que llegaron a tener cierta relevancia. Pese a ello, sin lugar a dudas, el intento más loable por restaurar la red expositiva en el ámbito parisino, se le debe a André Salmon, quien, con el patrocinio de Poiret, organiza la más relevante exposición de estas fechas en el Salon d'Antin del 109 de Faubourg Saint Honoré, bajo el título de Art Moderne en France². Una profundización en las pocas publicaciones de las que tenemos noticia sobre todas estas exposiciones demuestra dos cuestiones fundamentales. De un lado, la convicción por parte de crítica y público de 
que la mayor parte de ellas eran exposiciones de carácter marcadamente cubista; de otro, la imperiosa necesidad de superar el movimiento que, a tenor de lo expuesto, no tenía ya nada nuevo que aportar ${ }^{3}$.

A Léonce Rosenberg sin embargo, no le parecía que el cubismo no tuviese nada que aportar, más bien todo lo contrario. El joven y ambicioso marchante no duda en aprovechar la marcha de Kahnweiler para concitar en torno suyo a los cubistas que no habían marchado al frente como Gris y Picasso -además de a Metzinger, Braque y Léger cuando volvieron de él-, con el fin de abrir una galería exclusivamente cubista al fin de la guerra que habría de llamarse L'Effort Moderne. Además de ello, Rosenberg no duda en integrar en la aún iniciática galería a algunos artistas anteriormente cézannianos que justo en estos años deciden dar el salto al cubismo, como es el caso de María Blanchard, Jacques Lipchitz, Diego Rivera, Henri Laurens o Gino Severini. Y he aquí el quid de la cuestión. A aquellos de contrastada experiencia cubista se unían ahora algunos nuevos llegados que despiertan los recelos de puristas y detractores, que encuentran en ellos voluntades asociativas inducidas por cuestiones más de índole comercial que artístico.

Volvamos ahora a Reverdy. El poeta, fuertemente unido al cubismo desde su propia génesis, se suma de manera entusiasta al proyecto de Rosenberg y al cenáculo cubista, cada vez más amplio. Tal sería su ímpetu que la propia Nord Sud sería considerada por el resto de la crítica como el órgano teórico de la futura galería5, motivo por el cual resultan aún más incomprensibles sus invectivas. Asumida por parte del poeta la existencia de un único grupo cubista en torno a la figura de Rosenberg, sus afirmaciones solo pueden hacernos pensar en la posibilidad de que considerase que en él se hallaban intrusos.

Algunas cosas habían cambiado con anterioridad al estallido de la guerra. Muchas, en realidad. Los cubistas de salón y los contratados por Kahnweiler -considerados por muchos, líderes del movimiento- se fusionaban ahora en un único grupo al que se unían nuevos adeptos; las técnicas evolucionaban buscando nuevos caminos, el uso del color planteaba nuevas posibilidades, las temáticas se ampliaban... ¿Pero cómo reac- cionaron los propios cubistas ante estos cambios? ¿Quiénes de entre ellos influía sobre los demás? ¿Consideraban ellos mismos al igual que Reverdy que el grupo albergaba cubistas de primer y segundo orden? Veámoslo.

Temáticas afines: el auge del retrato femenino en el cubismo sintético. Relaciones entre vanguardia y tradición y más allá

Si volvemos sobre las proclamas de Reverdy y Ozenfant acerca de los retratos cubistas quizás debiéramos preguntarnos quién, de entre los cubistas, realizó un retrato de su mujer. Cuesta creer que Reverdy, tan unido a Juan Gris, se refiriera al madrileño, pero lo cierto es que éste había sido uno de los primeros en ahondar en las posibilidades retratísticas del cubismo durante estos años con su reinterpretación de Muchacha con mandolina de Corot de 1916, en el Kunstmuseum de Basel (fig. 1), que a su vez le serviría de modelo para el Retrato de Josette de 1917 del Reina Sofía de Madrid (fig. 2), a la sazón su mujer. Todo un despropósito para el madrileño si lo vemos desde esta óptica. Pero cuestionemos primero el por qué de estos retratos.

Los préstamos en las obras de Gris de 1916 y 1917, de composiciones análogas a los maestros de la tradición francesa -y en particular en Muchacha con mandolina-, se justifican por la obstinación plural y al tiempo pluralizada a todos los ámbitos de la vida durante estos años, incluido el artístico-cultural, de regresar a valores y modelos propios en un intento, si acaso absurdo, de encontrar refugio en lo conocido frente a lo devastador de la guerra6; el ya comentado imperativo de volver al orden. No son pocos los que, amparados en esta justificación, han estudiado los paralelismos entre la paleta cromática de Gris durante estos iniciáticos años de la guerra y la de Zurbarán', o que han insistido en lo apabullantemente ingresco de la producción cubo-clasicista de Picasso por las mismas fechas. La conjugación de clasicismo y vanguardia, en primera instancia quizás exclusivamente limitada a meros parámetros compositivos, es clara durante estos años. Además de ello, lo que no se puede negar es que los años de la guerra supusieron un boom del retrato femenino cubista. 


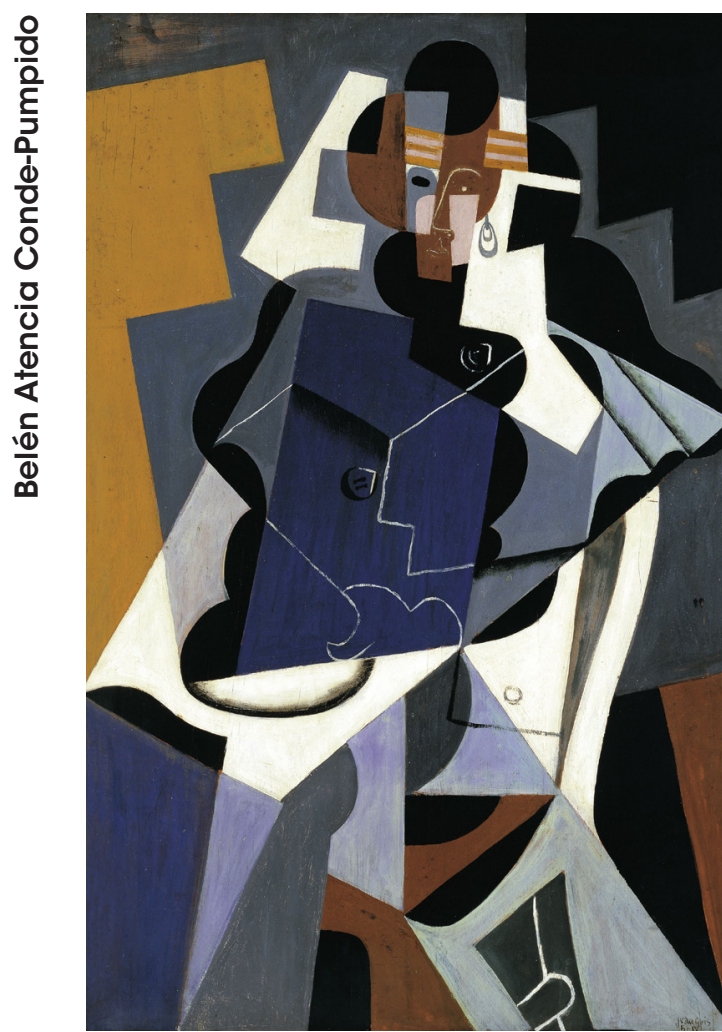

Fig. 3. Juan Gris, Mujer sentada, 1917, óleo sobre tabla, 116 x 73 Museo Thyssen-Bornemisza, Madrid

No sólo Gris vuelve a insistir con el ya mencionado Retrato de Josette de 1917; ese mismo año pinta Mujer sentada del Thyssen Bornemisza (fig. 3), diametralmente opuesta a las dos anteriores, en las que claramente podía apreciarse el ascendiente composicional clasicista. En Mujer sentada hay otras influencias. Nos sentiríamos tentados a decir que de tipo africano, sobre todo si atendemos a los rasgos faciales, similares a los de una máscara. ¿Influencias africanas en la obra de Gris? Nada encontramos en su obra anterior a estas fechas de mínimo influjo africano. Y sin embargo, en 1916, un año antes, Gris conoce a Lipchitz, escultor lituano que firma un contrato en exclusiva con Rosenberg ese mismo año pasando a formar parte del grupo cubista, quien además poseía una extensísima colección de arte africano y que terminaría por convertirse en uña y carne del pintors. No parece ser una casualidad.

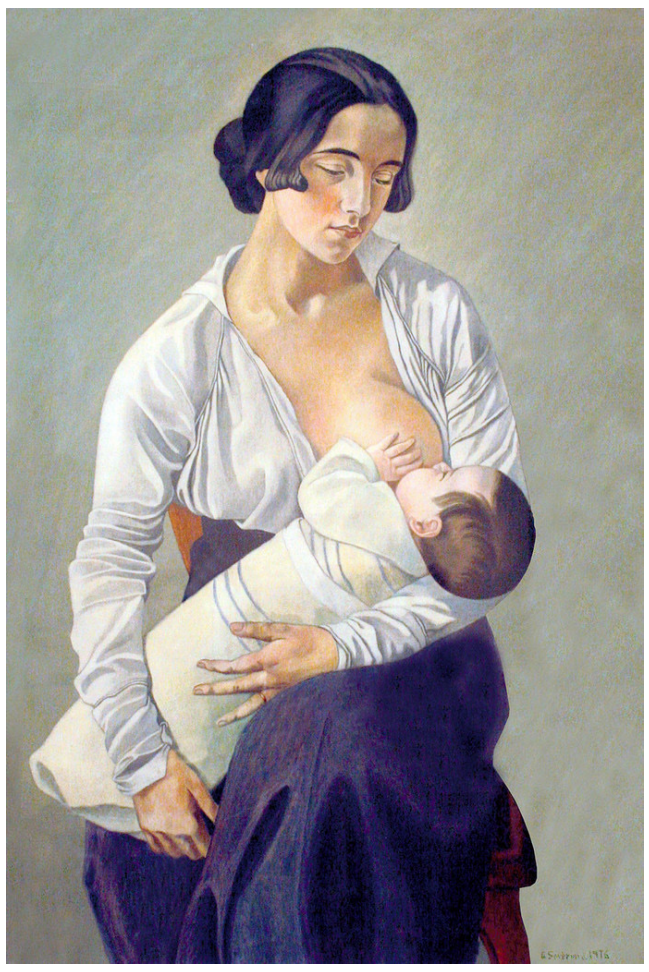

Fig. 4. Gino Severini, Maternidad, 1916, óleo sobre lienzo, 65 x 92 Museo de la Academia, Cortona

Pero volvamos por el momento a los retratos femeninos. Hablábamos de un boom.

Diego Rivera, María Blanchard y Gino Severini ahora reconvertidos al cubismo, participan igualmente de la tendencia retratística femenina, coincidiendo además en la factura de algunas maternidades ${ }^{9}$. Dos de ellas, ambas de Severini, nos interesan particularmente por la reflexión que suponen en torno a las posibilidades ofrecidas por la conjugación de vanguardia y tradición, además de constituir una flagrante evidencia de las claras oscilaciones del italiano entre ambas vertientes, que lo llevarían a involucrarse en el cubismo durante los años de la guerra y a virar a partir de los años veinte hacia el clasicismo ${ }^{10}$.

De un lado tenemos la Maternidad de 1916 del Museo de la Academia de Cortona (fig. 4), de claro corte clasicista, de otro Mujer con planta verde de 1917 en colección privada (fig. 5), cuyo título ha hecho sin lugar a dudas pasar por alto el hecho de que manifiestamente constituye la 


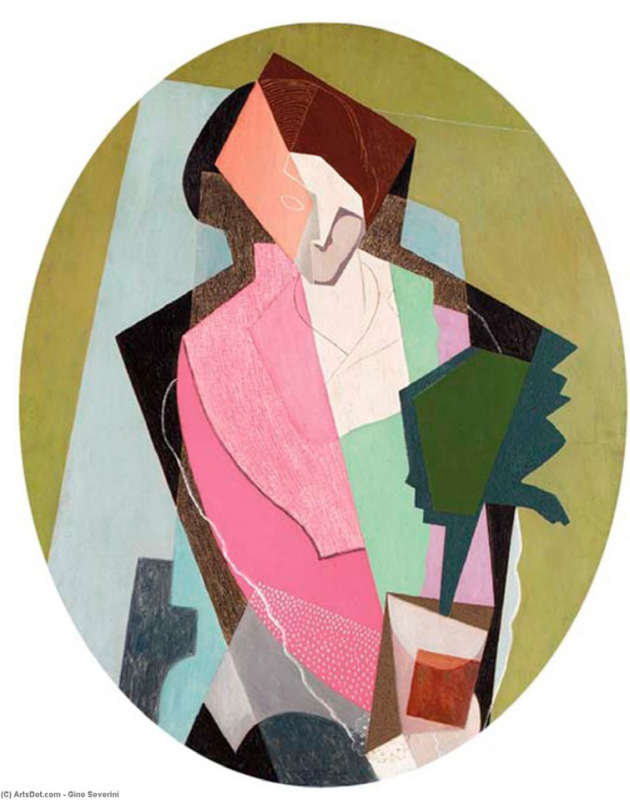

Fig 5. Gino Severini, Mujer con planta verde, 1917, óleo sobre lienzo, 60 × 92, colección privada

reinterpretación cubista de la anterior. Llaman particularmente la atención en ellas la exacta estructura composicional, la igual posición de la cabeza de las protagonistas, su idéntico peinado, su análoga manera de sujetar al bebé y a la planta, e incluso los equivalentes posicionamientos de éstos con respecto al seno de la protagonista. Comparemos ahora Mujer con planta verde y Retrato de Josette de Gris, y comprobaremos que se tratan juegos relacionales parecidos. En este caso, no es solo el motivo objeto del cuadro el equiparable; son los planos utilizados para su consecución los que nos hablan de un espíritu común en las obras de estos artistas y en las profundas reflexiones que la conjugación de modernidad y tradición supusieron para ellos.

La temática retratística femenina, con independencia de sus relaciones con composiciones de influjo clasicista, interesa particularmente a Severini"1. Entre 1914 y 1916 el pintor lleva a cabo una serie de dibujos, xilografías y aguafuertes, de muy similar composición y casi en su totalidad bajo el título de La Modista.

Una de sus modistas en particular, fechada en 1916 y conservada en el Art Institute of Chicago

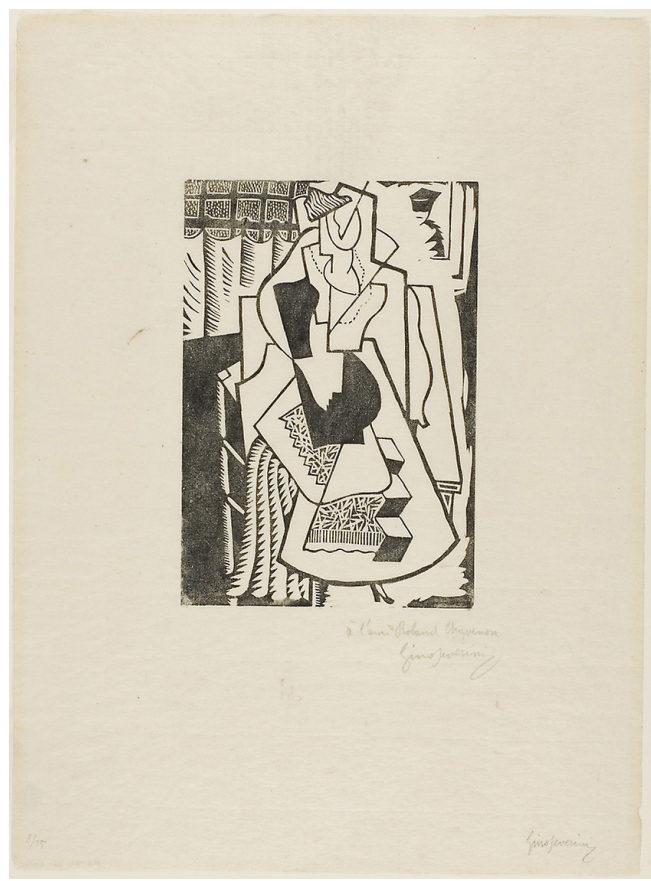

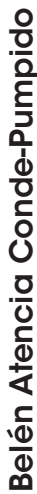

Fig. 6. Gino Severini, La Modista, 1916, xilografía sobre papel japonés, $18,3 \times 12,7 \mathrm{~cm}$, Art Institute of Chicago

(fig. 6), muestra a la protagonista de pie, frente al espectador. Tras ella, la mesa de trabajo donde se disponen las telas en las que trabaja. Algunos han apuntado que Picasso vio uno de estos diseños en casa de Apollinaire antes de marchar a Roma para la preparación de los decorados del Ballet Ruso de Parade y que éste influyó enormemente en La Italiana de la E.G. Bührle Collection (fig. 7) ${ }^{12}$. Otros, sin embargo, hallan mayores similitudes con Mujer con mandolina de Gris (Silver 1985, 49). Es cierto que hay detalles análogos entre estas dos últimas, no sólo a nivel compositivo, puesto que ambas comparten idéntica posición de tres cuartos; también los hay en la utilización de los planos que componen las figuras, sobre todo en aquellos que resuelven los hombros y el pecho de las protagonistas. Sin embargo, la propuesta de Picasso tiene un componente más prototípiCo, más vernáculo. El propio título del cuadro, La Italiana, nos está indicando que Picasso no está representando aquí la transposición cubista de Corot o de Ingres, sino la de una mujer de las muchas que pudiera haber visto en Roma durante su estancia o el arquetipo de todas ellas. O tal vez 


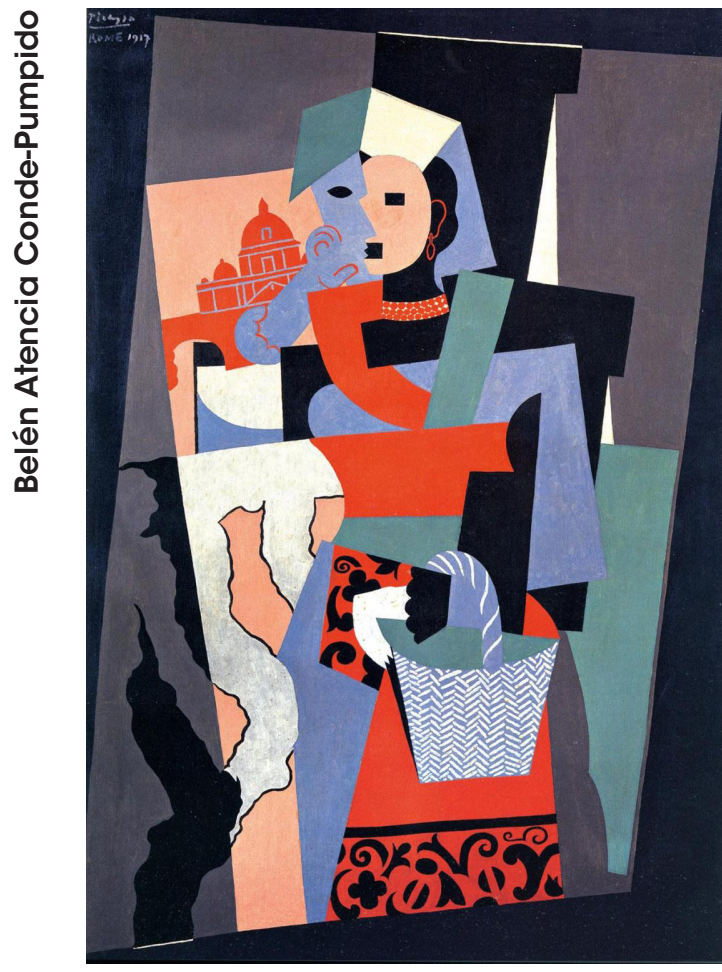

Fig. 7. Pablo Picasso, La Italiana, 1917, óleo sobre lienzo, 149 x 101,5 cm, E.G. Bührle Collection, Zurich

no; veamos qué sabemos acerca de las influencias en La Italiana. Sabemos, por los testimonios de una foto conservada en el Archivo Primoli de Roma, y una acuarela del pintor italiano Alberto Collina, que en los entornos de Plaza de España se reunían, vestidas a la manera tradicional italiana, vendedoras de flores que, al igual que la protagonista de Picasso, portaban su mercancía en cestas (Moncada 2007, 14). También sabemos que en Via Margutta, donde se hospedaba el malagueño, eran frecuentes las modelos, vestidas con traje regional prototípico del Lacio, que al igual que las anteriores repartían, en este caso fotografías propias en las que posaban ligeras de ropa, con la esperanza de encontrar trabajo entre los artistas (Moncada 2007, 14). Pero tratemos de ver más allá de la protagonista en sí. Tras ella, a través de lo que podemos intuir como una ventana, distinguimos la Basílica de San Pedro del Vaticano, que sitúa inequívocamente la escena. Carandente $(1981,49)$ ha querido ver aquí una clara alusión al Retrato de Madame Mallet de

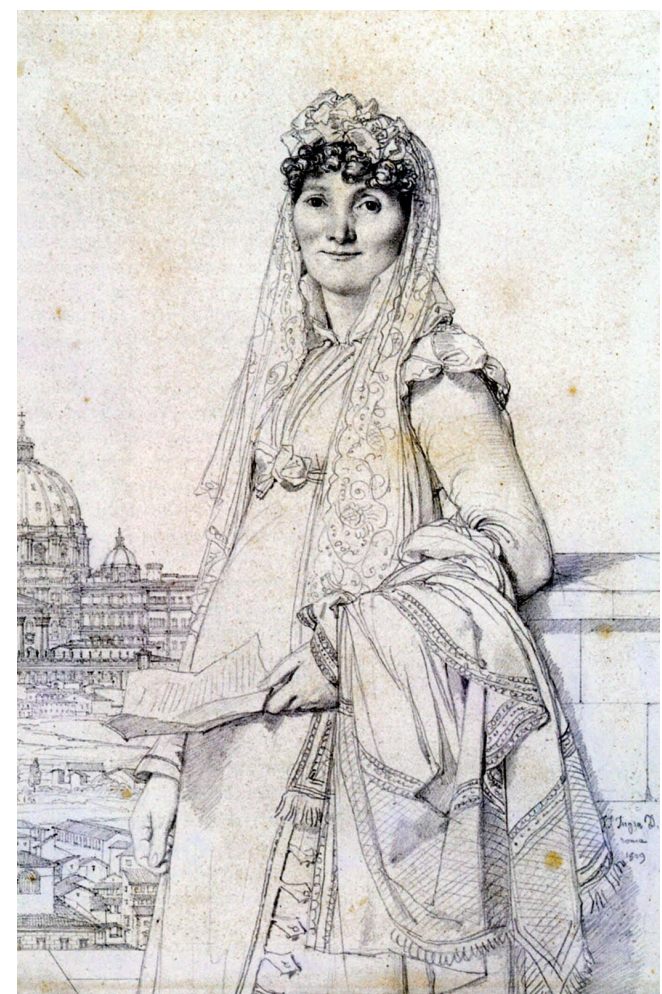

Fig. 8. Auguste Dominique Ingres, Retrato de Madame Mallet, 1809, grafito sobre papel, $29 \times 19,6 \mathrm{~cm}$, colección privada

1809 de Ingres (fig. 8), arguyendo que en las cartas que Jean Cocteau enviaba a su madre durante la estancia en Roma con Picasso, se afirma que el malagueño no dejaba de ensalzar al pintor francés, proclamando su primacía sobre los italianos (Cocteau 1917, 297). Que Picasso, consciente o inconscientemente, recurriese a influencias franco-tradicionalistas para la elaboración de $L a$ Italiana, ya fuesen a través de la obras de los propios maestros de la tradición francesa, ya fuesen a través de Femme à la mandoline de Gris, resulta sin lugar a dudas tentador para los historiadores del arte. Pese a ello, cuando nos referimos a Picasso y sus influencias, el abanico suele ser bastante más amplio. Es probable que Picasso tuviese a Ingres y a Corot presentes durante su estancia en Roma, y que además estuviese interesado por las posibilidades que sugería la revisión cubista de la obra de este último por parte de Gris. Es más que probable que Picasso viese a las vendedoras de flores de la Plaza de España en sus paseos con 


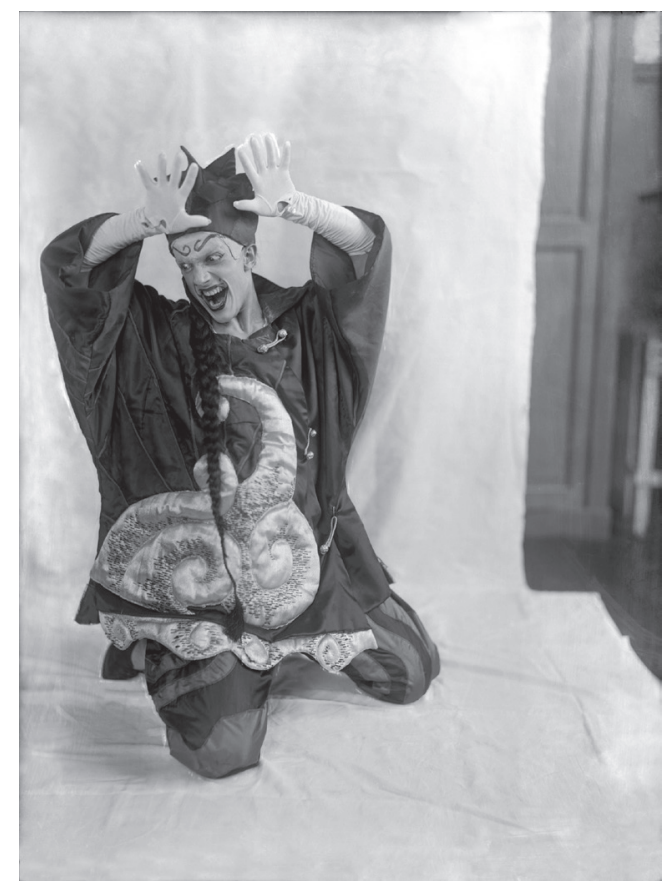

Fig. 9. Harry Lachman, Léonide Massine como prestidigitador chino en el Ballet Ruso de Parade, 1917, negativo fotográfico, Victoria \& Albert Museum, Londres

Cocteau y que viese, hablase y hasta pagase a alguna de las modelos de Via Margutta vestidas regionalmente para que posase para él. Quizás sea menos probable que el Retrato de Madame Mallet, con su vista de la Basílica de San Pedro lo inspirasen para La Italiana.

Volvamos de nuevo a La Modista de 1916 de Severini. Es complicado a primera vista saber si la indumentaria que lleva la protagonista responde a una tipología propia o si es el resultado de la conjugación de varias telas sobre las que pueda encontrarse trabajando, pero en apariencia resulta bastante similar a la de los trajes regionales italianos que Picasso pudo ver en Roma. Varios detalles son coincidentes en ambas composiciones. De una parte, el brocado de los trajes, muy similares entre ellos; de otra el hecho de que ambas protagonistas lleven collar -detalle que Picasso recuperará para el segundo gran lienzo resultante de su estancia en Roma, Arlequín y mujer con collar del Musée National d'Art Moderne de París-, y por último, la igualitaria resolución de los tocados. Pero no sólo esto. También

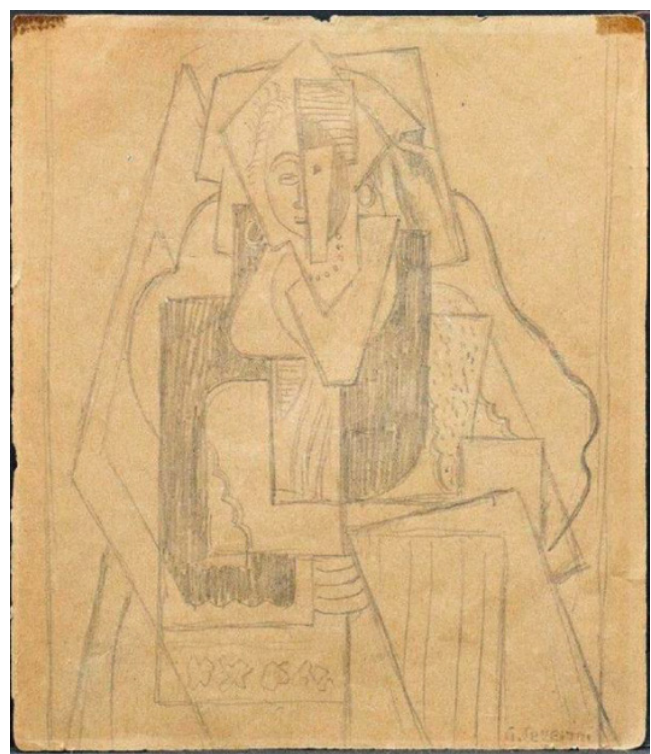

Fig. 10. Gino Severini, Estudio para Ciociara, 1918, grafito sobre papel, $16 \times 14 \mathrm{~cm}$, colección privada

en ambas composiciones podríamos decir que aparece una ventana. Podríamos decir porque la ventana real en La Modista se sitúa en el mismo lugar que en La Italiana, pero pareciera en este caso, que lo que Picasso retiene en su memoria como ventana es el póster en el que aparece representado el personaje chino a la derecha. De hecho, podríamos aventurarnos a decir que ese pequeño detalle, tan banal en apariencia, influyó en Picasso mucho más de lo que pareciese en un primer momento y no sólo en La Italiana. Así lo evidencia el que uno de los personajes principales de Parade, a quien estelarmente daría vida Léonide Massine, sería un prestidigitador chino al que hemos querido relacionar con Chung Ling Soo (fig. 9), ilusionista americano que se hacía pasar por chino, que ofrecía exitosos números de magia en París desde 1909, y que terminaría muriendo en 1918 de un tiro errado durante un espectáculo (Steinmeyer 2005). Parece por tanto probable que, tanto Picasso como Severini, ambos amantes de la Commedia dell'Arte, lo circense y la farándula, hubiesen frecuentado los espectáculos de Chung Ling Soo en París, que Severini lo retratase de manera casual en una de sus xilografías, que a su vez fuese vista por Picasso en el estudio de Apollinaire, y que una vez en Roma, Picasso, asi- 


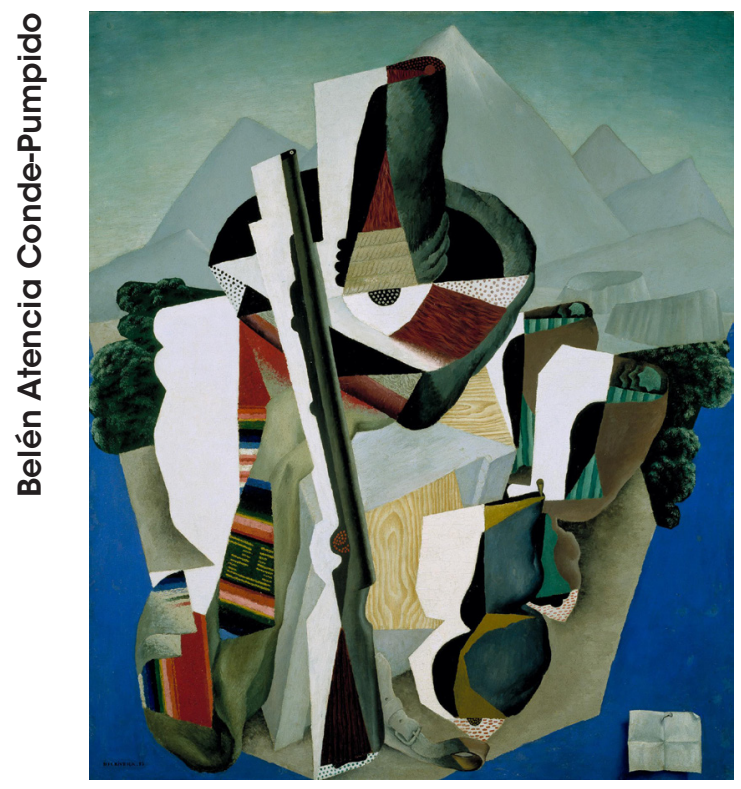

Fig. 11. Diego Rivera, Paisaje Zapatista, 1915, óleo sobre lienzo, 145 x 125, Museo Nacional de Arte, Ciudad de México

milador febril de injerencias ${ }^{13}$, se valiera de todo ello para la elaboración de La Italiana y de Parade.

No olvidemos volver ahora a Mujer sentada de Gris, aquella de aparentes influencias africanas. Carandente finalizaba las interrelaciones de Severini y Picasso en torno a La Italiana afirmando que, a su vez, ésta última serviría de modelo al italiano para La Ciociara de 1918, en colección privada. Comparen sin embargo Mujer sentada y Estudio para la Ciociara, en colección privada e igualmente datada en 1918 (fig. 10). No cabe duda de que Severini tuvo muy presente la obra de Gris para este estudio.

\section{¿Robos compositivos o similitudes com- posicionales?}

Hagamos por un momento un alto en el camino. Como hemos visto, tanto cubistas consolidados como recién llegados, se sienten atraídos por las posibilidades del retrato femenino y todos ellos, indiscriminadamente, influyen los unos sobre los otros. Hasta el momento por tanto, sin explicación fehaciente de el por qué de las acusaciones de Ozenfant y Reverdy.

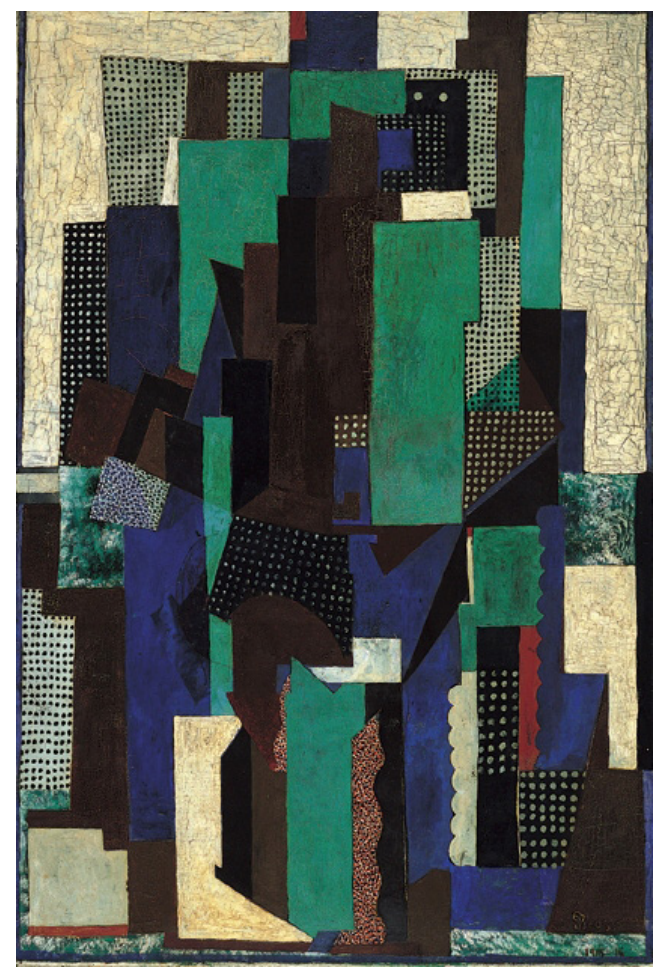

Fig. 12. Pablo Picasso, Hombre apoyado sobre una mesa, 1915, óleo sobre lienzo, 282 × 421, Pinacoteca Giovanni e Marella Agnelli, Turín

Sin embargo, sobre este último y sus publicaciones en Nord Sud deberíamos detenernos por un instante. En la aportación de Derouet para el catálogo de exposición de la muestra dedicada al Arte de América Latina organizada por el Pompidou hace ya algún tiempo (Derouet 1992, 60), se relatan los pormenores de la disputa mantenida entre Rivera y Reverdy en el transcurso de una cena en casa de André Lhote, que terminaría con la bofetada del primero al segundo, el orgullo herido del joven y henchido poeta y su consiguiente venganza, pluma en mano, en los sucesivos números de Nord Sud ${ }^{14}$.

Parece ser, y así lo defiende Derouet, que Rivera se sintió aludido ante las acusaciones de Reverdy acerca de los retratos cubistas y de ahí el resto de la historia. Es complicado estar seguros. Es cierto que el pintor vende a Rosenberg una serie de seis retratos que podrían haber sido sujeto de los ataques, pero el recibo de la compra 


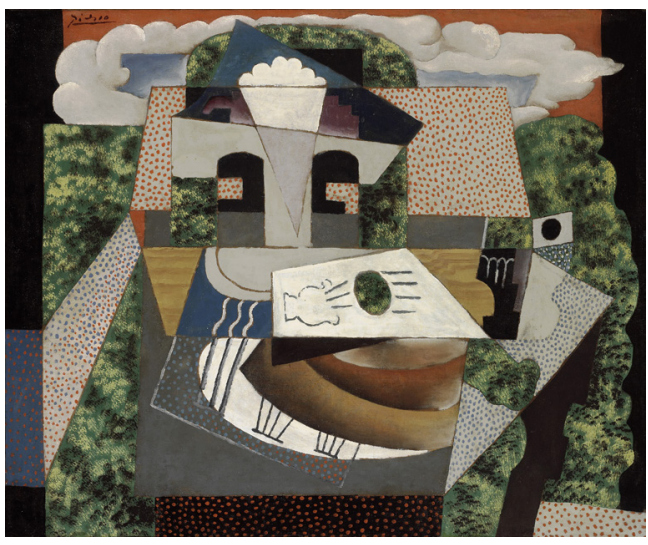

Fig. 13. Pablo Picasso, Naturaleza muerta con paisaje, 1915, óleo sobre lienzo, 140 × 120 cm, Meadows Museum, Dallas

tiene fecha de marzo de 1918 (Rivera, 1918) y no se conserva entre su correspondencia ninguno anterior a éste cuyo concepto sea el de retrato. El motivo que pudiera haber llevado a Rivera a sentirse aludido podría por tanto, haber sido otro. Y ciertamente, motivos existían.

El pintor no se había granjeado la mejor de las famas entre sus compañeros de galería. Muy unido a Picasso, con el que pasa tiempo discutiendo de arte y de política (Rivera, 1960, 104), no dudará sin embargo, en acusarlo frente a todos de robo compositivo. Y lo cierto es que resulta evidente la relación, tanto compositiva como formal, entre Paisaje Zapatista de 1915, en Museo Nacional de Arte Ciudad de México de Rivera (fig. 11) y Hombre apoyado sobre una mesa, del mismo año, en la Pinacoteca Giovanni e Marella Agnelli de Turín, de Picasso (fig. 12), tal y como indica Favela (1984, 103), o incluso Naturaleza muerta con paisaje del Meadows Museum de Dallas (fig. 13) como ha querido ver Hamill $(1999,68)$. Ello, unido al estrecho trato comercial de Rivera con algunos coleccionistas a espaldas de Rosenberg'15, y la considerada por sus compañeros de galería, superproducción de naturalezas muertas al estilo cubista, termina por enfrentar a muchos de ellos con el mejicano ${ }^{16}$. Los numerosos desencuentros entre unos y otros terminarían saldándose con la precipitada y no sencilla salida de Rivera del grupo cubista ${ }^{17}$.

Cierto es, por tanto, que no encontramos entre los recibos conservados en los fondos Rosen-

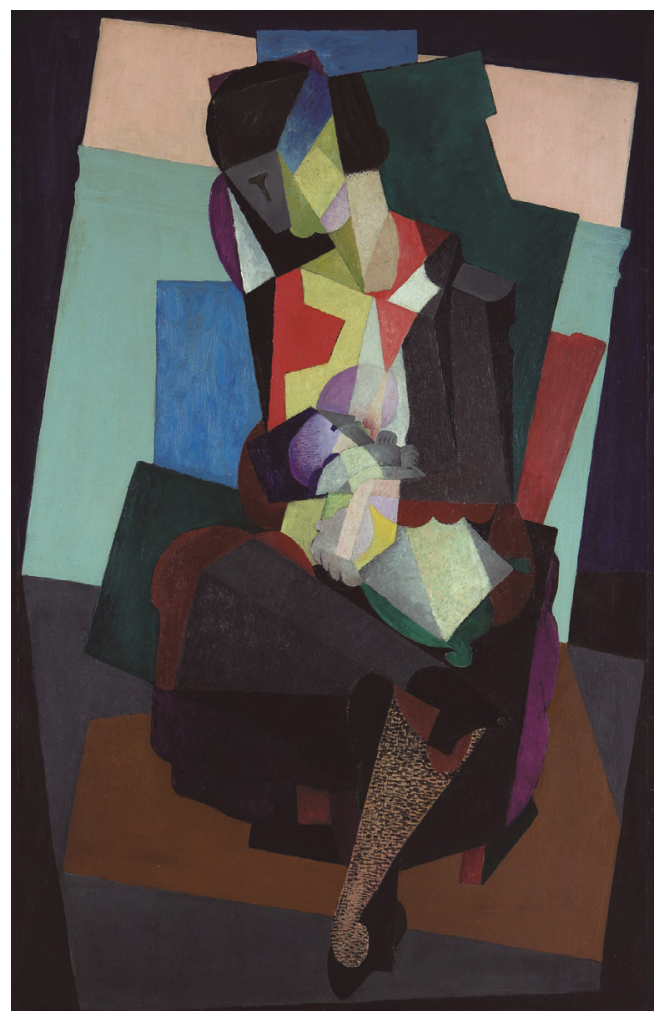

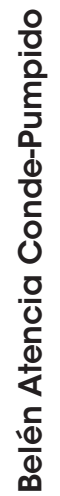

Fig. 14. Diego Rivera, Maternidad. Angelina y el niño Diego, 1916, óleo sobre lienzo, 134, 5 x 88,3, Museo de Arte Carrillo Gil, Ciudad de México

berg del Pompidou ninguno de ellos que atestigüe la factura de retratos por parte de Rivera en las fechas anteriores a la publicación del primer número de Nord Sud, pero sí sabemos que, al igual que Severini y Blanchard, éste lleva a cabo, al menos, una maternidad en la que se retratan a la por entonces su mujer, Angelina Beloff, y al pequeño que ambos tuvieron (fig. 14) y que moriría con poco más de un año, víctima de una neumonía sufrida durante un invierno que acuchilló a París. Quién sabe si la desazón provocada por heridas no cerradas pudiera haber hecho al pintor magnificar las afirmaciones de quien no dejaba de ser un joven y apasionado poeta.

\section{Conclusiones}

Hemos aquí ahondado en los préstamos e intercambios compositivos llevados a cabo por los cubistas del grupo Rosenberg en torno al re- 
trato en el cubismo sintético de los años de la guerra por lo para algunos, incomprensible de las afirmaciones de Reverdy y Ozenfant sobre el tema ${ }^{18}$, pero este artículo bien podría haber versado acerca de otro tipo de préstamos. Podríamos por ejemplo haber hablado sobre la análoga utilización de formas ondulantes, orgánicas, casi intestinales, que utilizaban Blanchard o Metzinger para conformar algunas de las botellas de sus bodegones ${ }^{19}$, y que estaban ya presentes en algunos de los dibujos de Picasso de 1915 y 1916 (Richardson 1996, 364); o de la utilización por parte de algunos de ellos de la decoración puntillista que invadió sus obras entre 1914 y 1916, y que les valió la consideración de cubismo rococó, tema al que Rabinow ha dedicado un interesantísimo ensayo recientemente ${ }^{20}$. Podríamos haber hablado del excepcional auge de la temática de la Commedia dell'Arte a partir de 1919, constante perenne en la obra de Picasso, quien reabre la veda con su alter ego, Arlequin del Museum of Modern Art de 1915. Precisamente arlequines son los que empiezan a aparecer en la obra de Blanchard sobre 1916. También lo hacen, de manera paralela, en las obras de Gris y Lipchitz (Amishai-Masisels 1974), quienes no habían nunca antes profundizado en esta temática, y quienes comparten con Blanchard y Metzinger la primavera y el verano de 1918 en Beaulieu-près-
Loches, huyendo de la Grosse Bertha²1. Capítulo aparte merecerían los intercambios entre Gris y Lipchitz, quienes tanto compartieron ${ }^{22}$. Capítulo aparte merecerían igualmente las interesantísimas interrelaciones que mantuvieron Braque y Laurens y que bien han valido la organización de ciertas muestras a tal efecto ${ }^{23}$, o lo que supuso para este último y para Gris la temática de las botellas en las construcciones del primero y los lienzos del segundo.

Salvando los posibles e inevitables desencuentros, lógicos entre colegas de profesión, y vencido el escollo del affaire Rivera, aquellos que embarcados antes de la guerra en la aventura cubista, y aquellos otros que lo hicieron con la llegada de ésta, muy probablemente no creyeron en rangos o distinciones. Todos ellos se reunían, discutían e intercambiaban. Todos prestaban y tomaban prestado. Todos creían en una nueva vida para el cubismo que pasaba por integrar vanguardia y tradición. ¿Y Reverdy y Ozenfant? Quizás nunca sepamos a quiénes se referían cuando hablaban de esos pseudo-cubistas. Tal vez se refirieran a Blanchard, Laurens o Severini. Tal vez sólo a Rivera. Tal vez a alguno de los exponentes del Salon d'Antin. Si le preguntásemos a Reverdy tal vez nos diría que ya ni siquiera lo recuerda. ¿Y en definitiva, tanto importa? 
NOTAS

1 A este respecto véanse Silver, Kenneth. 1990. Esprit de corps: The Art of the Parisian Avant-Garde and the First World War, 1914-1925. Princeton: Princeton University Press y Cabanne, Pierre. 2000. L'Epopée cubiste. Paris: Éditions de l'Amateur, 347.

2 Roskill, Marck. 1985. The Interpretation of Cubism, Londres: The Art Alliance Press, 97-98; Hubert, EtienneAlain. 1979. "Pierre Reverdy et le cubisme en mars 1917". Revue de l'Art, no. 43: 61 y ss.Fundamentales en el estudio de los grandes coleccionistas y galeristas de este período y la apertura de nuevas galerías son Gee, Mack. 1981. Dealers, critics and collectors of moderne painting: aspects of the parisian art market between 1910 and 1930. New York / Londres: Garland Publishing y Cabanne, Pierre. 2004. Les grands collectionneurs. Paris: Éditions de l'Amateur.

${ }^{3}$ Particularmente críticos fueron Roger Bissière y Louis Vauxcelles. El primero, decepcionado por los derroteros tomados por el cubismo que cree ver en estas exposiciones, el segundo por su odio visceral al movimiento y su gusto de corte impresionista que coincidirá con el de algunos de los exponentes como Marquet, Dufresnoy o Segonzac a los que defenderá entusiastamente. Buenos ejemplos de estas críticas son Bissière, Roger. 1916. «Le Réveil des Cubistes».L'Opinion (15 abril), id. 1916.»Organisons l'art français».L'Opinion (24 junio),id. 1916.»La logique et les expositions». L'Opinion (22 julio); Vauxcelles, Louis. 1916. «Quelques jeunes». L'Événement (28 julio), Pinturrichio [Vauxcelles, Louis]. 1916.»Chez Barbazanges». Le Carnet de la Semaine(6 agosto).

${ }^{4}$ Los pocos estudios a Rosenberg dedicados nos muestran un marchante exigente y cuadriculado que con sus incansables exigencias terminará por alejar de sí a la mayor parte de los artistas que en torno a él se aglutinaron. Particularmente críticos son los artículos y escritos en catálogos de exposición de Christian Derouet como 1982. «De la voix et de la plume. Les émois "Cubistes" d'un marchand de tableaux». Europe, revue littéraire mensuelle, no.
638-639 (junio-julio); id.1996.»Le Cubisme "bleu horizon" ou le prix de la guerre». Revue de l'Art, no. 113, así como en las introducciones de las publicaciones de las correspondencias del marchante con Gris y Léger en id. 1990. Juan Gris. Correspondances avec Léonce Rosenberg, 1915-1927. París: Les Cahiers du Musée National d'Art Moderne; id. 1996.Fernand Léger. Une correspondance d'affaires. París: Les Cahiers du Musée National d'Art Moderne. También crítico resulta Giovanni Casini en su simposio en 2017. "La " dittatura » di un mercante? Giorgio de Chirico, Léonce Rosenberg e il mercato dell'arte nella seconda metà degli anni Venti", Milán, 15 juino, y su versión inglesa 2017. "A dealer's « dictatorship »? Giorgio de Chirico, Léonce Rosenberg, and the Parisian art market in the late 1920's", Annual Third Year Postgraduate Symposium, Londres, 8 y 9 de junio. A este respecto véase igualmente, Atencia Conde-Pumpido, Belén. 2020, "Léonce Rosenberg y la idea de un cubismo colectivo en la Galería L'Effort Moderne durante la Gran Guerra". Arte, Individuo y Sociedad. no. 3 (junio-julio).

${ }^{5}$ A reforzar esta idea vendría la publicación de varios artículos de mano de los integrantes y/o simpatizantes de la galería, además del propio Reverdy. A este respecto véanse Reverdy. «Sur le cubisme»; id. 1918.»L'image». Nord-Sud. no.13 (marzo); Dermée, Paul. 1917. "Quand le Symbolismefut mort... «. Nord-Sud. no.1 (15 marzo); id. 1917.»Intelligence et Création». Nord-Sud no.7 (agosto-septiembre); Braque, Georges. 1917. "Pensées et réflexions sur la peinture". Nord-Sudno. 10 (diciembre). Para una profundización en la defensa teórica llevada a cabo por Reverdy, Rosenberg y Maurice Raynal, igualmente unido a la causa, véanse también Reverdy, Pierre. 1919. "Le Cubisme, poésie plastique". L'Art(febrero), Rosenberg, Léonce. 1919. Valori Plastici no.2-3 (febrero-marzo), id. 1920. Cubisme et Tradition, París: Éditions de I'Effort Moderne; id. 1921.Cubisme et Empirisme. París: Éditions de l'Effort Moderne; Raynal, Maurice. 1919. Quelques intentions du cubisme. París: Éditions de l'Effort Moderne.
${ }^{6}$ Véase a este respecto Green, Christopher. 1987. Cubism and its enemies. Modern Movements and Reaction in French Art 1916-1918. New Haven / Londres: Yale University Press, id. 2000. Art in France 1900-1940, New Haven / Londres: Yale University Press, y muy particularmente id. (dir.). 2016. Cubism and War: the Crystal in the Flame.exh cat., Barcelona: Museo Picasso.

7 Particularmente en1985. "Juan Gris, el cubismo y la idea de tradición”. In Juan Gris 1887-1927, cat. exh., Madrid: Salas Pablo Ruiz Picasso, 93. Esta idea ha sido recientemente retomada por Silver en 2014. "Juan Gris. Between cubism and classicism". In Cubism, The Leonard A. Lauder Collection, cat. exh., Nueva York: Museum of Modern Art, 196-201.

8 Anónimo. 1970. "African Art in the collection of Jacques Lipchitz". African Arts (verano). Sobre la relación entre pintor y escultor es fundamental la lectura de Green, Christopher. 1997. "Lipchitz y Gris: los cubismos de un pintor y un escultor". In Lipchitz. Un mundo sorprendido en el espacio, cat. exh., Madrid: Museo Nacional Centro de Arte Reina Sofía, 27-38.

9 Para el estudio de las incursiones de Rivera y Severini en el cubismo resultan interesantes las aproximaciones a sus autobiografías en Rivera, Diego. 1960. My Art, my Life. An Autobiography, New York: The Citadle Press; Severini, Gino. 1968. II Tempo de l'Effort Moderne. Florencia: Enrico Vallechi. Dos interesantes exposiciones se han celebrado sobre la producción cubista del mejicano, en 1984. Diego Rivera, The Cubist Years. cat. exh., Phoenix: Art Museum y 2004. The Cubist painting of Diego Rivera. Memory, Politics, Place. cat. exh., Washington: National Gallery of Arts. En el caso de Blanchard, inestimable resulta la aportación de Carmona Mato, Eugenio. 2013. "María Blanchard y la segunda vida del cubismo". In María Blanchard. cat. exh., Madrid: Museo Nacional Centro de Arte Reina Sofía, 41-65, y su comisariado en la más reciente 2017. María Blanchard, Juan Gris y los cubismos (1916-1927). cat. exh., Málaga: Museo Carmen Thyssen.

${ }^{10}$ Véase Coen, Elizabeth; Fagiolo del'Arco, Mauricio. 1977. Gino Severi- 
ni, un taccuino cubo-futurista, Roma: Bulzoni Editore y Fonti, Daniela. 1999. Opere inedite e capolavori ritrovati, Milán: Skira. El propio pintor abordaría estas diatribas en Severini, Gino. 1921. Du Cubisme au Classicisme, París: Povolozki Ed.

${ }^{11} \mathrm{El}$ interés por la representación de la mujer, y más particularmente de la mujer danzante ha sido profundamente estudiada por Fonti, Daniela. 2001. Gino Severini. La Danza, 1909-1916. cat. exh., Venecia: Peggy Guggenheim Collection.

${ }^{12}$ Daix, Pierre. 1977.La vie de peintre de Pablo Picasso, París: Éditions du Seuil, 155 y 159; Carandente, Giovanni. 1981. "Il viaggio in Italia: 17 febbraio 1917". In Picasso opere, dal 1895 al 1971 dalla collezione Marina Picasso. cat. exh., Venecia: Palazzo Grassi, 48.

${ }^{13}$ Para un acercamiento a las interesantísimas influencias entre Picasso, Cocteau, Satie y Massine, así como de cada uno de ellos a través de otras fuentes véase Kattner, Elizabeth Marie. 1997. The artistic collaboration resulting in the creation of the ballet Parade. Las Vegas: University of Nevada y Rothschild, Menaker. 1989. From Street to the Elite: Popular Sources in Picasso desings for "Parade". New York: Institute of Fine Arts.

${ }^{14} \mathrm{El}$ acontecimiento fue relatado por Max Jacob a Jacques Doucet y pronto se convirtió en la comidilla de los ambientes artísticos parisinos. Véase Jacob, Max. 1917. "Lettre à Jacques Doucet", Paris (22 marzo). In 1955. Correspondances. Paris: Les presses du réel, 145. Las fuertes críticas de Reverdy a Rivera, en las que se afirma que ha sidoexpulsado de su tribu por falta de apetito y fuerza viril, acusándosele de falta de valentía e inteligencia aparecen en Reverdy, Pierre. 1917. "Une nuit dans la plaine". Nord-Sud no.3 (15 mayo): 12 14.

${ }^{15}$ Lipchitz tratará de defender a Rivera explicándole a Rosenberg que éste se había limitado a vender obras previas a la firma del contrato entre ambos, pero el asunto no termina de quedar claro, en Lipchitz, Jacques. 1916. "Lettre à Léonce Rosenberg», Paris (lunes [febrero]). [C4 9600. 1014].París :Fonds Léonce Rosenberg, Musée National
d'Art Moderne Centre Georges Pompidou.

${ }^{16}$ Para conocer la opinión de los integrantes de L'Effort Moderne sobre Rivera y lo acaecido entre él, Reverdy y Rosenberg se hace fundamental la lectura de la correspondencia entre ellos y el marchante. Ejemplos de estas cartas son Gris, Juan. 1917. "Lettreà Léonce Rosenberg», París (27 marzo), París: Fonds Léonce Rosenberg, Musée National d'Art Moderne Centre Georges Pompidou; Braque, Georges. "Lettre à Léonce Rosenberg", Sorgues,[C20 9600. 35]. París: Fonds Léonce Rosenberg, Musée National d'Art Moderne Centre Georges Pompidou; Léger, Fernand. 1918. «Lettre à Léonce Rosenberg», Vernon (23 agosto). Nueva York: Archives Museum of Modern Art. In Derouet, Fernand Léger. Une correspondance d'affaires, 42.

${ }^{17}$ Para desgracia de Rosenberg, Vauxcelles, deseoso de arremeter contra el cubismo, no duda en suceder una batería de artículos en los que relata los pormenores de los desencuentros de éste con el mejicano y los consiguientes sinsabores de este. Véanse Pinturrichio [Vauxcelles, Louis]. 1918. "Le conflit du peintre et du marchand». Le Carnet de la Semaineno 156 (2 junio), id. 1918. «Désagrégation». Le Carnet de la Semaine no.157 (9 junio), id. 1918. «Exode».Le Carnet de la Semaine no.158 (16 junio), id.1918.»De Profundis».Le Carnet de la Semaine no.164 (28 julio), id.1918. «Perplexité». Le Carnet de la Semaine no.167 (18 agosto), id.1918. "Schisme». Le Carnet de la Semaineno.169 (1 septiembre)

18 Hubert por ejemplo propone que Reverdy haga referencia a los dibujos ingrescos de Picasso y Gris, en Hubert, «Pierre Reverdy et le cubisme mars 1917», 64.

${ }^{19}$ Sobre esta idea ha insistido por ejemplo Green en Cubism and its enemies. Modern Movements and Reaction in French Art 1916-1918, 29.

${ }^{20}$ La acepción de cubismo rococó, utilizado por primera vez por Barr, Alfred. 1966. Picasso: Fifty Years of his Art.cat. exh., Nueva York: Museum of Modern Art, fue posteriormente retomada por gran parte de la historiografía cubista para hacer alusión a las obras de Braque, Gris, Metzinger y sobre todo Picasso. Véase Rabinow, Rebecca. 2014. "Confetti cubism". In Cubism, The Leonard A. Lauder Collection, 156163.

${ }^{21}$ La particular simbiosis en la manera de concebir las formas abstractas que conformarían los motivos de sus obras durante este período por parte de estos artistas, no solo constituye en sí el tema central de la evolución del cubismo sintético durante los años de la guerra. Su procedimiento composicional daban al tiempo respuesta a las propuestas de Reverdy sobre el cubismo, -particularmente en Reverdy, "Le Cubisme, poésie plastique"-, base a su vez de los posteriores escritos de Raynal y Rosenberg sobre el tema. Para un acercamiento a estos escritos véase igualmente loc. cit, nota 7 .

22 Sabemos por Wilkinson que Lipchitz conoce a Gris a través de Modigliani, y que es gracias al madrileño como entra en contacto con Rosenberg y L'Effort Moderne, Wilkinson, Alan. 1996. The Sculpture of Jacques Lipchitz: a catalogue raisoné,vol. I, The Paris Years (1910-1930), Londres: Thames \& Hudson, 14. La relación entre ambos, como el propio Lipchitz dirá más adelante, será decisiva en su producción: "es un poco más tarde cuando conocí a Gris, en ese mismo 1916, en un momento en el que era maduro para aceptar los tabúes y las limitaciones de los cubistas ortodoxos", Lipchitz, Jacques. 1947. (27 mayo). In Yvars, Juan Francisco; Ybarra, Lucía (eds.). 1997. Letters to Lipchitz and some personal notes by the artist. Madrid: Museo Nacional Centro de Arte Reina Sofía , 237-249. Tan intensa y profunda será la relación entre ambos que Lipchitz no dudará en reprochar a Kahnweiler el poco peso que el marchante le otorga en la biografía de Gris que publicase en 1946: "Nada disminuirá la gloria pura de Gris, si tenemos en cuenta que los años 19161919, los cuales eran creativos para ambos, eran fecundados por nuestras entusiastas energías entremezcladas de manera fraternal. Por mi parte, bendigo al cielo de haberme concedido este privilegio. Realmente usted piensa que una amistad como la nuestra, entre dos artistas creadores, únicamente tuvo efectos unilaterales, hasta el punto que 
sólo me puede usted dedicar en su libro esta modesta, pequeña mención en la página 234: "Hubo un escultor, Jacques Lipchitz, que fue amigo de Gris". Le he demostrado más arriba que yo era más que esto. Espero que el porvenir no ratifique su sentencia...", ibidem, 249. Sobre esta inestimable relación véase Green, "Lipchitz y Gris: los cubismos de un pintor y un escultor", 27-38, y para conocer algunos métodos de trabajo similares entre Gris y Lipchitz véase igualmente Stott, Deborah. 1978. Jacques Lipchitz and Cubism. Nueva York / Londres: Garland Publishing Inc, 137.

${ }^{23}$ Monod-Fontaine, Isabelle; Ramond, Sylvie (dir.).2005. Braque \& Laurens. Un dialogue autour des collections du Centre Pompidou. cat.exh., París: Musée National d'Art Moderne, Centre Georges Pompidou. Véanse sobre este tema Taillandier, Yves. 1951.»Une déclaration de Henri Laurens». Amis de l'Artno.1 (26 junio) y Laurens, Henri. 1952.»Henri Laurens, témoinage». XXe siècle (2 enero). 
Préstamos, intercambios y robos compositivos en el cubismo sintético parisino

\section{REFERENCIAS}

Amishai-Masisels, Zivah. "Lipchitz and Picasso: Thematic Interpretations." Journal of Jewish Art 1 (1974).

Anónimo. "African Art in the collection of Jacques Lipchitz." African Arts (Verano 1970).

Atencia Conde-Pumpido, Belén. "Léonce Rosenberg y la idea de un cubismo colectivo en la Galería L’Effort Moderne durante la Gran Guerra." Arte, Individuo y Sociedad 32 no. 3 (Junio-Julio 2020): 625-640. https://doi. org/10.5209/aris.64156

Barr, Alfred. Picasso: Fifty Years of his Art. Cat. exh. New York: Museum of Modern Art, 1966.

Bissière, Roger. "Le Réveil des Cubistes.» L'Opinion, Abril 15, 1916.

Bissière, Roger. "Organisons I'art français.» L'Opinion, Junio 24, 1916.

Bissière, Roger. "La logique et les expositions.» L'Opinion, Julio 22, 1916.

Braque, Georges. «Pensées et réflexions sur la peinture.» Nord-Sud 10 (Diciembre 1917).

Braque, Georges. "Lettre à Léonce Rosenberg», Sorgues, [C20 9600. 35]. Paris: Fonds Léonce Rosenberg, Musée National d'Art Moderne Centre Georges Pompidou.

Cabanne, Pierre. L'Epopée cubiste. Paris: Éditions de l'Amateur, 2000.

Cabanne, Pierre. Les grands collectionneurs. Paris: Éditions de l'Amateur, 2004.

Carandente, Giovanni. "Il viaggio in Italia: 17 febbraio 1917." In Picasso opere, dal 1895 al 1971 dalla collezione Marina Picasso, 48. Cat. exh. Venecia: Palazzo Grassi, 1981.

Carmona Mato, Eugenio. "María Blanchard y la segunda vida del cubismo." In María Blanchard, 41-65. Cat. exh., Madrid: Museo Nacional Centro de Arte Reina Sofía, 2013.

Carmona Mato, Eugenio. María Blanchard, Juan Gris y los cubismos (1916-1927). Cat. exh. Málaga: Museo Carmen Thyssen, 2017.

Casini, Giovanni, "A dealer's « dictatorship »? Giorgio de Chirico, Léonce Rosenberg, and the Parisian art market in the late 1920's." Annual
Third Year Postgraduate Symposium, London (8 y 9 de junio 2017).

Cocteau, Jean. «Lettre» (22 febrero 1917). In Lettres à samère I (1898-1918), 297. Paris: Gallimard, 2017.

Coen, Elizabeth; Fagiolo del'Arco, Mauricio. Gino Severini, un taccuino cubo-futurista, Roma: Bulzoni Editore, 1977.

Daix, Pierre. La vie de peintre de Pablo Picasso, Paris: Éditions du Seuil, 1977.

Dermée, Paul. "Quand le Symbolisme fut mort... « Nord-Sud 1, Marzo 15, 1917.

Dermée, Paul. «Intelligence et Création.» NordSud 7, Agosto-Septiembre, 1917.

Derouet, Christian. «De la voix et de la plume. Les émois "cubistes" d'un marchand de tableaux.» Europe, revue littéraire mensuelle 638-639 (Jjunio-Julio 1982); id. 1996.

Derouet, Christian. Juan Gris. Correspondances avec Léonce Rosenberg, 1915-1927. Paris: Les Cahiers du Musée National d'Art Moderne, 1990.

Derouet, Christian. «Diego Rivera ou comment être o un 'être plus cubiste.» In Art d'Amérique Latine 1911-1968. Cat. exh. Paris: Musée National d'Art, Centre Georges Pompidou, 1992.

Derouet, Christian. Fernand Léger. Une correspondance d'affaires. Paris: Les Cahiers du Musée National d'Art Moderne, 1996.

Derouet, Christian. "Le Cubisme "bleu horizon" ou le prix de la guerre.» Revue de l'Art 113 (1996): 40-64. https://doi.org/10.3406/ rvart.1996.348280

Favela, Ramon (dir.). Diego Rivera, The Cubist Years. Cat. exh. Phoenix: Art Museum, 1984.

Fonti, Daniela. Opere inedite e capolavori ritrovati. Milán: Skira 1999.

Fonti, Daniela (dir.). Gino Severini. La Danza, 1909-1916. cat. exh. Venecia: Peggy Guggenheim Collection, 2001.

Gee, Mack. Dealers, critics and collectors of moderne painting: aspects of the parisian art market between 1910 and 1930. New York / London: Garland Publishing, 1981. 
Gris, Juan. «Lettre à Léonce Rosenberg.» París (Marzo 27, 1917). Paris: Fonds Léonce Rosenberg, Musée National d'Art Moderne Centre Georges Pompidou.

Green, Christopher. "Juan Gris, el cubismo y la idea de tradición." In Tinterow, Gary (ed.). Juan Gris 1887-1927. Cat. exh. Madrid: Salas Pablo Ruiz Picasso, 1985.

Green, Christopher. Cubism and its enemies. Modern Movements and Reaction in French Art 1916-1918. New Haven / London: Yale University Press, 1987.

Green, Christopher. "Lipchitz y Gris: los cubismos de un pintor y un escultor." In Lipchitz. Un mundo sorprendido en el espacio, 27-38. Cat. exh. Madrid: Museo Nacional Centro de Arte Reina Sofía, 1997.

Green, Christopher. Art in France 1900-1940. New Haven / London: Yale University Press, 2000.

Green, Christopher (dir.). Cubism and War: the Crystal in the Flame. Cat. Exh. Barcelona: Museo Picasso, 2016.

Hamill, Pete. Diego Rivera. New York: Harry N. Abrams, Inc. Publishers, 1999: 68.

Hubert, Etienne-Alain. «Pierre Reverdy et le cubisme en mars 1917.» Revue de l'Art 43 (1979): 61 y ss.

Jacob, Max. «Lettre à Jacques Doucet.» Paris (22 marzo 1917). In Correspondances, 145. Paris: Les presses du réel, 1955.

Kattner, Elizabeth Marie. The artistic collaboration resulting in the creation of the ballet Parade. Las Vegas: University of Nevada, 1997.

Laurens, Henri. «Henri Laurens, témoinage.» XXe siècle, Enero 2, 1952.

Léger, Fernand. "Lettre à Léonce Rosenberg.» Vernon (Agosto 23, 1918). New York: Archives Museum of Modern Art.

Lipchitz, Jacques. "Lettre à Léonce Rosenberg.» París (lunes [Febrero] 1916). [C4 9600. 1014]. Paris: Fonds Léonce Rosenberg, Musée National d'Art Moderne Centre Georges Pompidou.

Lipchitz, Jacques. 1947 (Mayo 27, 1947). In Yvars, Juan Francisco; Ybarra, Lucía (eds.). Letters to
Lipchitz and some personal notes by the artist, 237-249. Madrid: Museo Nacional Centro de Arte Reina Sofía, 1997.

Moncada, Valentina. Picasso a Roma. Milán: Electa, 2007.

Monod-Fontaine, Isabelle, et Sylvie Ramond (dirs). Braque \& Laurens. Un dialogue autour des collections du Centre Pompidou. Cat. exh. Paris: Musée National d'Art Moderne, Centre Georges Pompidou, 2005.

Ozenfant, Amédée. «Notes sur le cubisme». L'Elan 10 (Dicembre 1, 1916): 6.

Pinturrichio [Vauxcelles, Louis]. «Chez Barbazanges.» Le Carnet de la Semaine (Agosto 6, 1916).

Pinturrichio [Vauxcelles, Louis]. «Le conflit du peintre et du marchand». Le Carnet de la Semaine 156 (Junio 2, 1918).

Pinturrichio [Vauxcelles, Louis]. «Désagrégation.» Le Carnet de la Semaine 157 (Junio 9, 1918).

Pinturrichio [Vauxcelles, Louis]. «Exode.» Le Carnet de la Semaine 158 (Junio 16, 1918).

Pinturrichio [Vauxcelles, Louis]. «De Profundis.» Le Carnet de la Semaine 164 (Julio 28, 1918).

Pinturrichio [Vauxcelles, Louis]. «Perplexité.» Le Carnet de la Semaine 167 (Agosto 18, 1918).

Pinturrichio [Vauxcelles, Louis]. «Schisme.» Le Carnet de la Semaine 169 (Septiembre 1, 1918).

Rabinow, Rebecca. "Confetti cubism". In Cubism, The Leonard A. Lauder Collection, 156163. 2014.

Raynal, Maurice. Quelques intentions du cubisme. Paris: Éditions de l'Effort Moderne, 1919.

Reverdy, Pierre. "Sur le cubisme.» Nord Sud 1 (Marzo 15, 1917).

Reverdy, Pierre. «Une nuit dans la plaine.» NordSud (Mayo 15, 1917): 12-14.

Reverdy, Pierre. "L'image." Nord-Sud 13 (Marzo 1918)

Reverdy, Pierre. «Le Cubisme, poésie plastique.» L'Art (Febrero). 
Richardson, John. A life of Picasso, 1907-1917. The painter of modern life, New York: Random House, 1996.

Rivera, Diego. «Lettre à L. Rosenberg.» Marzo 4, 1918). [10422. 1286]. Paris: Fonds Léonce Rosenberg, Musée National d'Art Moderne Centre Georges Pompidou.

Rivera, Diego. My Art, my Life. An Autobiography. New York: The Citadle Press, 1960.

Rosenberg, Léonce. Valori Plastici 2-3 (FebreroMarzo 1919).

Rivera, Diego. Cubisme et Tradition. Paris: Éditions de l'Effort Moderne, 1920.

Rivera, Diego. Cubisme et Empirisme. Paris: Éditions de l'Effort Moderne, 1921.

Roskill, Marck. The Interpretation of Cubism. London: The Art Alliance Press, 1985.

Rothschild, Menaker. From Street to the Elite: Popular Sources in Picasso desings for "Parade". New York: Institute of Fine Arts, 1989.

Severini, Gino. Du Cubisme au Classicisme, Paris: Povolozki Ed., 1921.

Severini, Gino. II Tempo de l'Effort Moderne. Florencia: Enrico Vallechi, 1968.

Silver, Kenneth. "Juan Gris y su arte en la Gran Guerra, 1914-1918." In Tinterow, Gary (ed.). Juan Gris 1887-1927. Cat. exh. Madrid: Salas Pablo Ruiz Picasso, 1985.
Silver, Kenneth. Esprit de corps: The Art of the Parisian Avant-Garde and the First World War, 1914-1925. Princeton: Princeton University Press, 1990.

Silver, Kenneth. "Juan Gris. Between cubism and classicism." In Cubism, The Leonard A. Lauder Collection. Cat. exh. New York: Museum of Modern Art, 2014: 196-201.

Steinmeyer, Jim. The Glorious Deception: The Double Life of Wiliam Robinson, Aka Chung Ling Soo, the "Mavelous Chinese Conjuror". New York: Carroll and Graf Publishers, 2005.

Stott, Deborah. Jacques Lipchitz and Cubism. New York / London: Garland Publishing Inc, 1978.

Taillandier, Yves. «Une déclaration de Henri Laurens.» Amis de l'Art 1 (Junio 26, 1951).

Tinterow, Gary (ed.). Juan Gris 1887-1927. Cat. exh. Madrid: Salas Pablo Ruiz Picasso.

The Cubist painting of Diego Rivera. Memory, Politics, Place. cat. exh., Washington: National Gallery of Arts.

Vauxcelles, Louis. "Quelques jeunes.» L'Événement (Julio 28, 1916).

Wilkinson, Alan. The Sculpture of Jacques Lipchitz: a catalogue raisoné, vol. I, The Paris Years (1910-1930). London: Thames \& Hudson, 1996. 